\title{
Özel Yetenekli Bir Çocuğun Ebeveyni Olmak
}

\author{
AYCA KÖKSAL
}

\begin{abstract}
"Özel yetenekli çocuklar zaman ister. Genelde sizden daha az uykuya ihtiyaç duyarlar, cevaplayabileceğinizden çok soru sorarlar, sizden günün 24 saatinde \%100 dikkat isterler, ilgi alanlarında takıntılıdırlar, her şeye çok derin tepkiler verirler. Normal sınıf ortamlarında çok zorlayıcı olabilirler, kendileri ve sizler için çok mükemmeliyetçi standartlar belirlerler. Diğer birçok çocuk ayakkabısını nasıl bağlayacağını öğrenmeye çalışırken onlar, hayatın anlamını anlamaya ve öğrenmeye çalışırlar. İyi bir ebeveyn olmak için, sınırsız sabra, ansiklopedik bir zihne ve sizin için uyuyacak birisine ihtiyacınız olacaktır."

Linda SILVERMAN
\end{abstract}

Özel yetenekli çocuklar dünyayı diğerlerinden daha farklı görme ve algılama yeteneğine sahiptirler. Geleceğe iz bırakacak çocuklar olmaları da bu yeteneklerinden kaynaklanır. Ancak bunun gerçekleşebilmesi onları anlayan bir çevre yaratmaktan, uygun eğitim şartlarını sunmaktan ve hayal kurmalarına izin vermekten geçer. Bu sebeple özel yetenekli çocuklara dair olabildiğince çok konuşulmalı ve toplumda farkındalık yaratma çalışmaları sürekli devam etmelidir. Bu makalede de amaç, özel yetenekli çocukların fark edilmesinde ve yönlendirilmesinde kilit rolde olan ebeveynlerin farkındalıklarının arttırılması ve yaşayabilecekleri sorunların incelenmesidir. Anne babalar, çocukların hayatlarındaki en önemli figürlerdir. Yapılan birçok araştırma, uygun, özenli ve güven veren ebeveynliğin çocuğun gelişimde çok önemli olduğunu göstermektedir. Çocuklara uygun ilgi ve

- GÖRÜS- 
özen gösterildiğinde, gerçek tutkularını bulma, anlamlı yaşamlar geliştirme ve seçtikleri topluma katkıda bulunma şansı olduğu, uygun ebeveynlik almayan veya kendi düzenine bırakılan çocukların ise o kadar şanslı olmayabileceği ve çoğu zaman kendi kimliklerini bulmakta daha fazla zorlanacakları söylenebilir (Klein, 2007). Bu doğrultuda, bugün çocuğumuz için, çocuğumuz adına yapılacak her şeyin gelecekte bir etkisi olduğunu düşünebiliriz.

Ebeveynlik birçok ebeveyn için zorlayıcı ve karmaşık bir roldür. Ancak özel yetenekli bir çocuğun ebeveyni olmak, bu rolün karmaşıklığını ve zorluğunu biraz daha arttırmaktadır. Bunun sebebi, özel yetenekli çocukların sahip oldukları kendilerine has gelişim özellikleri ve bu özelliklere uygun gereksinimleridir. Özel yetenekli çocuklar, evde veya okulda yaşıtlarından farklı davranır, arkadaşlık kurmakta ya da devam ettirmekte sorun yaşayabilir veya okulda sıkılabilirler. Özel yetenekli çocuğa sahip ebeveynler çocuklarını tanımaya ve ona ayak uydurmaya çalışırken bir yandan da çevresel şartları çocuklarına uygun hale getirmek için mücadele ederler. Ancak bunu başarmaya çalışırken çoğu zaman kendilerini yalnız hissederler. Çünkü çocuk gelişimi ile ilgili birçok kaynakta doğrudan özel yetenekli çocuklar ve ebeveynlerine yönelik oldukça az sayıda içerik bulunmaktadır. Tüm bunlar ve daha da fazlası özel yetenekli çocuğun ebeveynini de, özel yetenekli çocuk kadar ayrıcalıklı ve sorumlu kılar.

Özel yetenekli bir çocuğa sahip olmanın anne babaya getireceği spesifik sorunlardan bahsetmek gerekirse, en başta "asenkronize gelişim" den söz etmek gerekmektedir. Asenkronize gelişim, çocuğun tüm gelişim yüzlerinin (fiziksel, bilişsel, duygusal, sosyal) birbirinden farklı seviyede olma durumudur. Normal gelişim gösteren çocukların gelişimleri kronolojik yaşına paralel ilerler ancak özel yetenekli çocuklarda durum farklıdır. Örneğin, 9 yaşında bir zihne sahip 6 yaşındaki bir çocuk, 9 yaşında bir çocuk gibi çizmek ve yazmak ister, ancak fiziksel gelişimi yaşına uygundur. Veya 8 yaşında bir çocuk, ölüm ve sosyal adalet gibi zor kavramları bilişsel olarak anlayabilir, ancak bu kavramları ele alacak yaşam deneyimine (duygusal gelişim) sahip olmayabilir. Başlı başına bu eş zamansızlık hem çocuğu hem de ebeveynini zorlayan bir durumdur. Bu gelişim özelliğinin yaratacağı sorunlarla başa çıkmak için ebeveynlere şunlar yardımcı olabilir:

1. Çocuğun güçlü yönlerine odaklanmak.

2. Özel yetenekli olmanın anlamını çocukla konuşmak ve anlamasına yardımcı olmak.

3. Gerçekçi beklentiler oluşturmak (Her alanda aynı başarıyı gösteremeyeceği gerçeğini unutmamak). Ebeveynler, kendisiyle derin bir felsefi tartışmaya giren çocuğunun, kısa bir süre sonra 
kardeşiyle basit bir sorun yaşadığı için ağlamasını anlamlandıramaz ve çoğu zaman "çocuk gibi davranıyorsun" gibi cümlelerle aslında beklentilerinin ne kadar yüksek olduğunu gösterirler. Böylece hem çocuk hem ebeveyn ciddi denebilecek bir akıl karışıklığı yaşarlar. Bu durumda yapılması gereken en önemli şey; "Çocuğun kronolojik yaşını unutmamaktır”. Bununla birlikte çocuğun farklı gelişim alanlarında farklı ihtiyaçlarının olduğunu bilmek durumla baş etmeyi kolaylaştıracaktır.

4. Çocuğun iletişim kuracağı farklı akran grupları bulmak (Bir grup, bilişsel gelişimine yakın olanları içerirken bir diğeri benzer ilgi alanlarını içerebilir).

5. Benzer sorunlar yaşayan ebeveynlerle iletişim kurmak.

Özel yetenekli bir çocuğun ebeveyni için en büyük sorunlardan birisi aslında çocuklarının tanılanmasıyla birlikte başlar. Bu sorun, “Özel Yeteneklilik Tanısının” çocukla paylaşılıp paylaşılmaması gerektiğidir. Bir grup ebeveyn bu durumu bir sır gibi saklarken, bir diğer grup ise tüm ilişkilerini bu tanı üzerinden yeniden kurgular. Aslında her iki ebeveyn grubunun davranışı üzerinde düşünmek gerekir. Kronolojik yaşının üzerinde bir zihne ve yetişkine yakın muhakeme yeteneğine sahip bir çocuğun, farklılığını fark etmeyeceği ironisi üzerine kurgulanan sır gibi saklama tutumu, çocuğun kendisini çok daha garip ve "sorunlu" hissetmesine yol açacaktır. Diğer yandan tanılanma sürecinden sonra, anne baba çocuk ilişkisinin tamamen bu özellik üzerinden yeniden şekillenmiş olması da, çocuğun kendi benliğini değersiz hissetmesine ve sahip olduğu bu özelliği (bir nevi etiketi) asla kaybetmemesi gerektiğini düşünmesine sebep olacaktır. Bu amaçla başarısız olma korkusuyla onun için yeni olan şeyleri denemek istememek, riske girmemek, bildiği sularda yüzmek isteyecektir. Bu noktada "o zaman bu durumu çocuğumuzla nasıl paylaşmalıyız?” sorusu gündeme gelir ve oldukça kıymetli bir sorudur. Galbarith'in 1985 yılında, bir grup özel yetenekli gençle yaptığı araştırmada gençlerin ilk sırada belirttikleri sorun "özel yetenekli oluşun ne demek olduğunun onlarla paylaşılmaması” olmuştur. Yine 2016'da Douglas tarafından yürütülen ve 300 özel yetenekli gençle çalışılan bir araştırmada;

- \%33'ü hiç kimsenin özel yeteneklilik hakkında onlarla konuşmadığını,

- \%43'ü hiç kimsenin farklılaştırılmış eğitimin sebeplerini onlara anlatmadığını,

- \%55’i hiç kimsenin eğitim kariyerinde onlara kendi sorumluluğunu almalarına izin vermediğini ifade etmiştir. 
Buradan da anlaşılmaktadır ki, özel yetenekli çocuğa sahip ebeveynin ilk öğrenmesi gereken şeylerden biri bu durumu çocuğuyla nasıl paylaşabileceğidir. Bu konuda ebeveynlere yardımcı olabilecek birkaç ipucu şöyle sıralanabilir:

1. Öncelikle bilinmesi gereken şey şudur, ebeveynler çocuklarının farklılığının özel yetenekli oluşundan kaynaklandığını bilir. Ancak bunu bilmeyen çocuklar kendilerinin garip, tuhaf, sıra dışı olduğunu hisseder. Bu sebeple kendini "normalleştirmeye", garip olmamaya çalışır. Aynı zamanda bu garip veya tuhaf etiketi arkadaşları tarafından da onunla paylaşılır. Çoğu zaman akranları onları söz konusu olan "garip" hareketleri ya da konuşmaları sebebiyle eleştirir veya aşağılar. Bu sebeple, özel yeteneklilik durumu çocukla "uygun" biçimde paylaşılmalıdır.

2. Ebeveynlerin çoğu zaman özel yetenekli, üstün zekalı, zeki, dahi gibi terimleri kullanmakta çekindikleri görülür ki bu haklı bir endişedir. Bu terimler yerine, hızlı öğrenen, belli alanda yetenekli, ilgili, potansiyeli gelişmiş gibi terimler kullanılabilir.

3. Özel yetenekliliğin paylaşımı bir özellik paylaşımından çok, çocuğun güçlü ve zayıf yanlarının paylaşımı şeklinde olmalıdır. Çocuğa, sadece hızlı öğrendiği veya yetenekli olduğunu söylemek yerine, hangi alanda yetenekli olduğu, hangi becerilerinin gelişmiş olduğu ve geliştirilmesi gereken noktalarının neler olduğu söylenmelidir.

4. Çocukla özel yeteneklilik konuşulurken, "herkesin farklı ve biricik olduğu, farklı öğrenme stilleri ve ilgilere sahip olduğu, bazı konularda birilerinden iyiyken, bazı konularda başkalarının ondan iyi olabileceği ve özel yetenekli oluşun her alanda yüksek performans göstermek olmadĭ̆ı" mutlaka ifade edilmelidir.

5. İyi bir dinleyici olmanın çok önemli olduğu unutulmamalıdır. Çocuklarının özel yetenekli oluşlarıyla ilgili ne düşündüklerini, ne hissettiklerini, yaşadıkları güçlüklerin neler olduğunu paylaşmaları teşvik edilmelidir.

6. Ayrıca sahip olunan potansiyelin değişmez olmadığı da mutlaka paylaşılmalıdır. Zekanın dinamik özelliğe sahip olduğu ve çabanın, düzenli çalışmanın, istikrarın kazanılacak başarıda kimi zaman zekadan bile önemli olduğu vurgulanmalıdır.

Özel yetenekli çocukların yaşadıkları güçlüklerden bir diğeri ise sosyal etkileşim veya arkadaşlık problemleridir. Bu güçlük çoğu zaman ebeveynler için de zorluk yaratır. Çünkü yaşıtlarıyla iletişim kurmakta zorlanan çocuğun yaşadığı duygusal problemler ilk ve en yoğun olarak ebeveyne yönelir. 
Asenkronize gelişim gösteren özel yetenekli çocuklar, sosyal iletişim kurmak için başka özel yetenekli çocuklara, daha büyük yaştaki çocuklara, hatta yetişkinlere ihtiyaç duyar. Özel yetenekli çocukların arkadaşlık beklentileri de kronolojik akranlarından farklıdır. Onlar, yakın, dürüst, güvenli ve gerçek arkadaşlıkları akranlarından çok daha önce arayabilirler. Bu arayış akranlarına oranla yaklaşık 4-5 yıl erken gelişir. Bu sebeple özel yetenekliler literatüründe arkadaşlık problemleri önemli bir yer teşkil etmektedir. Çocuklarının arkadaşlık ilişkilerine ebeveynler nasıl katkıda bulunabilirler?:

1. Öncelikle ebeveynler çocuklarının herkesle arkadaşlık kurmasını beklemekten vazgeçmelidirler. Çocuklarının seçici olabileceğini, belli kriterler arayabileceğini unutmamalıdırlar. Çocuklarına yardımcı olmak için kendi seçtikleri gruplara çocuklarını sokup orada arkadaşlık kurmasını beklemek yerine, çocuklarının ilgi alanlarını doğru anlayıp ilgilerinin uyuşacağı gruplara yönlendirmek çok daha doğru olacaktır. Bu yönlendirmede kronolojik yaş yerine ilgi alanları daha öncelikli olabilir.

2. Kendi gibi olan özel yetenekli çocuklarla buluşabileceği gruplar aramak ve bu gruplarla çocuklarını tanıştırmak önemli olabilir (Özel yetenekli çocukların devam ettiği yaz/kış okulları, ilgi alanlarına uygun kurslar vb.).

3. Bu önlem ve müdahalelere rağmen, çocuklar halen arkadaşlık kurmakta zorlanıyorsa altta yatan başka bir psikolojik problem (sosyal kaygı, yoğun utangaçlık, depresyon vb.) olma ihtimali akılda tutulmalıdır. Böyle bir durumda profesyonel bir destek almak en doğru seçenektir.

Özel yetenekli çocukların, problem yaşamasına sebep olabilecek bir başka gelişimsel özellikleri ise mükemmeliyetçi olmalarıdır. Davis' e (2006) göre özel yetenekli mükemmeliyetçi bireyler, her zaman daha iyisinin yapılabileceğine inandıkları için performanslarından memnun olmamaktadırlar. Silverman' a göre (1993) ise özel yetenekli çocuk kendine ulaşılması zor ölçütler belirler, ancak henüz bedeni yeteri kadar gelişmiş olmadığı için beynin ihtiyaçlarını karşılayamaz ve böylece cesareti kırılır. Mükemmeliyetçi kişilik özelliği birçok araştırmada depresyon, obsesif kompulsif kişilik bozukluğu, anksiyete bozuklukları ve yeme bozuklukları ile ilişkilendirilmiştir (Greenspan, 2000; Anthony ve Swinson, 2000).

Mükemmeliyetçilik özelliği, ebeveynler ve öğretmenler için oldukça karmaşık ve zorlayıcı olabilir. Ama özel yetenekli çocuklar için hem olumlu (sağlıklı) hem de olumsuz (sağlıksız) sonuçlar doğurur. Sağlıksız mükemmeliyetçilik stres, ulaşılması zor beklentiler, riskten kaçınma ve 
erteleme ile ilişkilendirilirken sağlıklı mükemmeliyetçilik, yüksek düzeyde başarı ve akademik performans ile ilişkilidir. Sağlıklı mükemmeliyetçilik sergileyen çocukların yüksek özgüvene sahip oldukları da söylenebilir (Adelson, 2007).

Bu doğrultuda sağlıksız mükemmeliyetçilik özelliğine sahip özel yetenekli çocukların ebeveynleri çocuklarına şu şekilde yardımcı olabilirler:

1. Ebeveynler, çocuklarının sağlıksız mükemmeliyetçilikten sağlıklı mükemmeliyetçiliğe geçiş yapmalarına yardımcı olmak adına öncelikle sonuç odaklı olmaktan süreç odaklı olmaya geçiş yapmaları gerekir. Bununla anlatılmak istenen şey, çocuklarının ortaya koydukları ürünlerde veya çıktılarda elde ettikleri başarıdan çok o ürünü hazırlarken yaşadıkları duygulara gösterdikleri çabaya odaklanmaktır. Başka bir deyişle, tamamlanmış bir işle ilgili kendileriyle gurur duymalarına yardımcı olmak sağlıksız mükemmeliyetçiliği azaltabilir.

2. Sağlıksız mükemmeliyetçiliği yüksek olan özel yetenekli bir çocuğa öğretilebilecek en etkili şey, hata yapmanın güzel olduğudur. Çocuğun hata yaparken aslında yeni bir şey öğrendiğinin vurgulanması, hata yapma veya başarısız olma korkusunu azaltabilir. Bu amaçla ebeveynin model olması önemlidir. Kendi anne babasının hata yaptığını gören ve bununla sağlıklı baş ettiğine şahit olan çocuk kendisi de hata yapmaktan korkmayacak ve sağlıklı bir şekilde baş edebilecektir.

3. Özel yetenekli çocukların doğuştan getirdiği mükemmeliyetçilik özelliği çoğu zaman sağlıklıdır. Yetişme esnasında sağlıksız mükemmeliyetçiliğe evrilen durumlarda kesinlikle sosyal öğrenmeden söz etmek gerekir. Kısacası sağlıksız mükemmeliyetçiliğe sahip çocukların anne babalarında veya onlara bakım veren yetişkinlerde de sağlıksız mükemmeliyetçiliğe rastlama ihtimali yüksektir.

4. Sağlıksız mükemmeliyetçiliğe sahip özel yetenekli çocuklar için işe yarayabilecek bir diğer öneri ise, hedef belirlemelerine yardımcı olmak ve hedeflerini küçük adımlara bölmelerini istemek olabilir. Özel yetenekli çocukların, birçok alanda başarılı olmalarını sağlayan çok yönlülük özellikleri hedeflerini küçük adımlara bölmelerini zorlaştırabilir. Bu nedenle anne babanın model olması ve rehberlik etmesi çok önemlidir.

5. Sağlıksız mükemmeliyetçiliği azaltmak için öğretmenlerle işbirliği içinde olmak gerekir. Çünkü özel yetenekli çocuklar için bu durum çoğu zaman, okul ortamında daha fazla belirginleşir ve onlara 
zarar verebilecek hale dönüşebilir. Ayrıca, psikolojik problemler gözlemlendiği noktada profesyonel bir destek sağlanması şarttır. Sağlıklı bir yetişkin olmak için sağlıksız mükemmeliyetçiliğin sağlıklı mükemmeliyetçiliğe evrilmesi gerekir.

Özel yetenekli bir çocuğun ebeveyni olmak, bilinmeyen bir yolda haritaya bile sahip olmadan araba kullanmaya benzer. Çok iyi bir şoför olunsa bile bu yolda kişinin karşısına neler çıkacağı bilinmez. Yanlış yola sapılabilir, kaza yapılabilir ve bu belirsizlik ciddi anlamda kaygı yaratan bir durumdur. Kaygıyı azaltmak için benzer yolda sürüş yapan başka şoförlerle konuşulabilir, onların deneyimlerinden faydalanılabilir. Ancak herkesin yolu ve sürüşü kendisine ait ve biriciktir. Dolayısıyla yapılabilecek en doğru şey yolu anlamaya ve tanımaya çalışmak olacaktır. Özel yetenekli çocukları anlamak ve tanımak için bilgi edinmek, okumak, gelişmek çok önemlidir. Bazen de sadece onları gözlemlemek ve öğretmelerine izin vermek...

\footnotetext{
"Hedefe yalnız çocukları yetiştirmekle ulaşamayız! Çocuklar geleceğindir. Çocuklar geleceği yapacak adamlardır. Fakat geleceği yapacak olan bu çocukları yetiştirecek analar, babalar, kardeşler hepsi şimdiden az çok aydınlatılmalıdır ki, yetiştirecekleri çocukları bu millet ve memlekete hizmet edebilecek, yararlı ve faydalı olabilecek şekilde yetiştirsinler! Hiç olmazsa yetiştirmek lüzumuna inansınlar! Okullardan başka; gazeteler, küçük dergiler köylere kadar yayınlanıp dağıtılmalıdır. Bizim köylümüz ne gazete ne dergi okumaz. Bilenler bilmeyenleri toplayıp, okutmayı, onlara okumayı anlatmayı bir vazife bilmelidir."
}

Mustafa Kemal ATATÜRK

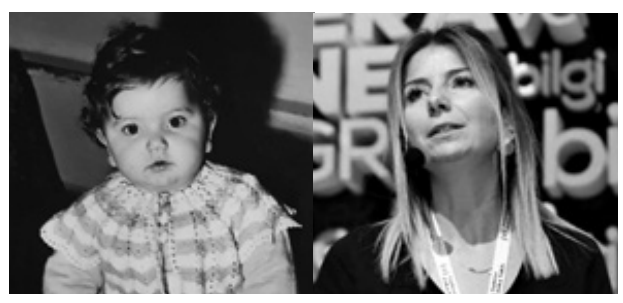

Ayça Köksal

\section{Kaynakça}

Adelson, J.L., (2007). A Perfect Case Study: Perfectionism in Academically Talented Fourth Grades, Gifted Child Today, Vol.30, No. 4, 14-20.

Antony, M. M. ve Swinson, R. P. (2000). Mükemmeliyetçilik Dost Sandığımız Düșman. (Cev.: A. Açıkgöz). İstanbul: Kuraldıșı Yayıncılık.

Davis, G.A. (2006). Gifted children and gifted education: A practical guide for teacher and parents. Scottsdale, AZ: Great Potential Press, Inc.

Douglas, D. (2016). 30 Things Parents \& Gifted Kids Need to Know, Parenting for High Potential, Vol.5 (4). 
Galbraith, J. (1985). The eight great gripes of gifted kids: Responding to special needs. Roeper Review, 8(1), 15-18.

Greenspan, T. S. (2000). Healthy perfectionism is an oxymoron. Journal of Secondary Gifted Education, 11(4), 197-209.

Klein, B. (2007). Raising Gifted Kids: Everything you need to know to help Your Exceptional Child Thrive, AMACOM, New York

Silverman, L. K. (1993). Social development, leadership, and gender issues. In L. K. Silverman (Ed.), Counseling the gifted and talented, (s. 291 - 327). Denver, CO: Love Publishing. 